than the level of $2 \mathrm{mgm} . / \mathrm{kgm}$. usually employed elsewhere, in prolonged courses, the toxicity of 'Hetrazan' was tested on two hundred Africans free from filariasis and it was concluded that doses considerably higher than those usually employed could safely be given. Extonsive surveys have been made of the incidence of infection of $L$. loa and other filarial infections both in human beings and in Chrysops, the vector spocies, in the Kumba and Bamenda divisions in the Cameroons and elsewhere, and the wide distribution of Chrysops in Africa has been noted, including its presence in areas where loiasis is not a problem.

A disturbing development in malaria therapy in Malaya has been the appearance of proguanilresistant strains of $P$. falciparum. The Hot Climate Physiology Laboratory at Oshodi, Nigeria, has been completed and equipped, and studies have been made on the ability of native-born West Africans to work in severe heat and humidity, the effect of arterial occlusion upon the sweat rate and sweat composition, the metabolic costs of common tasks, blood chemistry and daily sweat loss in routine tasks. Physiological research at Makerere College, Uganda, has included red blood cell counts of students and the preparation of precipitin sera; investigations have been carried out of tick-borne relapsing fever, and the success of chloromycetin in the treatment of scrub typhus has been amply confirmed. A field research unit based on the Institute for Medical Research, Kuala Lumpur, Malaya, is making a long-term study of serub typhus.

The fifth annual report of the Committee for Colonial Agricultural, Animal Health and Forestry Research reviews the regional agricultural research, as under the East African Agricultural and Forestry Research Organization, where work is being done in mycology, including a study of the canker disease of cypresses, and where absence of staff has impeded the research into the sudden death disease of the clove trees. The individual research projects are assisted from Colonial Development and Welfare Funds and research work is undertakon as part of the programme of Colonial departments. Under the banana research scheme administered by the Imperial College of Tropical Agriculture, Trinidad, work on the breeding of male parents carrying the factors of immunity to Panama disease has reached a stage at which little further progress can be made until the projected expedition to south-east Asia can take place; and under the cocoa research scheme, similarly administered, work is procceding on the completion of testing the I.C.S. clones, the establishment of a collection of cacao types, of Theobroma species and allied types, and breeding of improved strains, including those resistant to witches broom. Individual research projects include the appointment of an officer in charge of termite research in the Colonios to study termites in the field and train entomologists for this specialized work, in the first place in East Africa. In British Guiana manuria] research in progress aims at the solution of the phosphate problem, while in the Federation of Malaya mech anical cultivation trials of rice received special consideration. On the Gold Coast, research into lime die-back disease has shown that a virus is responsible, that most sweet citrus is capable of carrying it and that $A$ phis citricidus Kirkaldy ( $A$, tavaresi del Guercio) is one of the vectors. In Mauritius, research is being carried out to find means of eontrolling or eradicating the introduced shrub Cordia macrostachya (Jacq.), which is a serious weed in sugar plantations; also clonal selection trials are in progress at the Lya. munga Coffee Research Station, Tanganyika. Reports are also included from the standing Cocoa Research, Soils and Stored Products Sub-Committees.

The Colonial Insecticides, Fungicides and Herbicides Committee appointed two new sub-committees during the year, one to consider problems relating to herbicides and arboricides (including defoliants) and the other to deal with defoliants. Arrangements have been made with the Imperial College of Science and Technology, London, and the Agricultural Research Council for fundamental work on insecticides to be conducted at the Imperial College Field Station, Silwood Park, and at Rothamsted Experimental Station. Preliminary work on a number of the newer insecticides has been agreed on, and the establishment of a Colonial Insecticides Research Unit in West Africa is recommended. A study of the behaviour of mosquitoes in huts treated with DDT and $\mathrm{BHC}$ has commenced, and also of the effect of partial defoliation of the bush in tsetse concentration areas on tsetse control and the disinfestation of trains against tsetse. The work of the Colonial Insecticides Research Team, Porton, on aqueous suspensions of insecticides, the formation and properties of DDT crystals, the toxicity of compound 497 , 'Chlordan' and 'Toxaphene', and the fumigant action of insecticides, and that of the Colonial Insecticides Research Unit, East Africa, on tsetse, mosquitoes and malaria, and malaria eradication in Mauritius are reviewed in some detail.

The third annual report of the Colonial Economic Research Committee records that arrangements for research projects into the national income of Nigeria, the problems arising from the dependence of certain Colonial territories upon imported foods and on transport economics in relation to economic develop. ment, with special reference to Nigeria, are well under way; difficulty in securing suitable research workers has continued to be a principal hindrance to progress. Other schemes in progress at the end of the year were Dr. J. Greqves's inquiry into Colonial monetary systems, and an investigation by Mr. P. T. Bauer of the organization of trade in West Africa.

\section{FIFTIETH ANNIVERSARY OF THE NOBEL FOUNDATION}

$\mathrm{O}^{\mathrm{N}}$ December 10, the Nobel Foundation celebrated its fiftieth anniversary. Alfred Nobel, a man of great vision and unique generosity, and most keenly interested in the welfare of mankind, wished his discovery of dynamite, the most potent explosive of his time, and the huge estate collected through its manufacture, to benefit peace and progress. To achieve this he directed that his estate after his death should constitute a fund, the interest of which would be distributed annually in the form of prizes to those who, during the preceding year, shall have conferred the greatest benefit on mankind. The interest was to be divided into five equal parts, and apportioned as follows : one part to the person who shall have made the most important discovery or invention within the field of physies; one part to the person who shall have made the most important chemical discovery or improvement; one part to the person who shall have made the most important discovery within the 
domain of physiology or medicine; one part to the person who shall have produced in the field of literature the most outstanding work of an idealistic tendency; and one part to the person who shall have done the most or the best work for fraternity among nations, for the abolition or reduction of standing armies and for the promotion of peace.

The prizes for physics and chemistry were to be awarded by the Swedish Academy of Science; that for physiology or medical work by the Caroline Institute in Stockholm; that for literature by the Academy in Stockholm; and that for champions of peace by a committee of five persons to be elected by the Norwegian Storting.

Nobel added that it was his wish that in awarding the prizes no consideration whatever should be given to the nationality of the candidates, so that the most worthy should receive the prize, whether he be a Scandinavian or not. Later it was realized that in practice a prize could not be awarded for work done during the preceding year only. The rules of the Nobel Foundation were correspondingly amended, stating that: the provision in the will that the annual award of prizes shall refer to work during the preceding year shall be understood in the sense that the awards shall be made for the most recent achievements in the fields of culture referred to in the will, and for older works only if their significance has not become apparent until recently.

In his contribution to a volume just published, entitled "Nobel : The Man and His Prizes" (Stockholm : Sohlmans Förlag), Liljestrand, who for the past thirty-two years has filled the important post of secretary of the Medical Nobel Committee, emphasizes the marked similarity between certain expressions in Nobel's will and the regulations governing the Rumford Medal, which is awarded by the Royal Society in London "to the author of the most important discovery or useful improvement . . . made during the preceding two years on heat or light, the preference always being given to such discoveries as ... tend most to promote the good of mankind". It seems probable that these directives served as a model for Nobel when he began to plan his awards for new and important contributions to human welfare in certain scientific or other cultural fields.

Competence to submit proposals for the award of Nobel Prizes for Physics and Chemistry is enjoyed by : (1) Swedish and foreign members of the Royal Academy of Science; (2) members of the Nobel Committees for Physics and Chemistry; (3) men of science who have been awarded a Nobel Prize by the Academy of Science; (4) professors of physics and chemistry in several Scandinavian universities; (5) holders of corresponding chairs in at least six universities or corresponding institutions selected by the Academy of Science with the view of ensuring the appropriate distribution of the commission over the different countries and their seats of learning; and (6) other men of science from whom the Academy may see fit to invite proposals, an authorization of which the Academy makes use on generous lines.

Competence to submit proposals for the award of the Nobel Prize for Physiology and Medicine is enjoyed by : (1) members of the teaching body of the Caroline Institute; (2) members of the medical class of the Royal Academy of Science ; (3) previous recipients of the Nobel Prize for Physiology and Medicine ; (4) members of medical faculties of several Scandinavian universities; all the bodies which are named above under (5) and (6).
That good use is made of these generous competence statutes of the Nobel Foundation is shown by the fact that in the course of the past fifty years as many as 872 names have been suggested as recipients of the Nobel Prize for Physiology and Medicine alone.

While the ultimate responsibility for the distribution of the Prize for Physics and that for Chemistry lies with the Swedish Academy of Sciences and for the Prize for Physiology and Medicine with the Caroline Institute (Medical Faculty), much of the responsibility is borne by the special committees appointed to advise these institutions. The members of these committees carry out a heavy and difficult task in scrutinizing the large number of proposals submitted. In 1950 the number of nominations for the Prizes for Physics, Chemistry and Physiology and Medicine were as high as 56,72 and 113 respectively.

General merit alone in promoting science does not qualify for obtaining a Nobel Prize. Several contributions by the same person but in different fields, none of which is important enough by itself to qualify for an award, are not considered. It is after recognizing the fundamental importance of a discovery that it is ascertained who is or are responsible for that qualifying advance. The statutes of the Nobel Foundation thus do not exclude the possibility of one person obtaining more than one Nobel Prize.

However, only one Nobel laureate has so far obtained more than one prize; that was Marie Curie, who received one and a quarter awards. The Physics Prize in 1903 was shared by Becquerel and by Pierre and Marie Curie, half of the prize being allotted to Becquerel. In 1911 the Chemistry Prize was very appropriately awarded to Marie Curie, "for her services to the advancement of chemistry by the discovery of the elements radium and polonium, by the isolation of radium and the study of the nature and compounds of this remarkable element". As Irene Joliot-Curie and Frederic Joliot obtained the Chemistry Prize in 1935 "for their synthesis of new radioactive elements", the Curie family has received no less than five Nobel Medals, which may remain a record for all time.

The history of the Nobel Foundation covers much of the history of physics, chemistry and medicine of the past fifty years.

The awarding institutions very happily chose Röntgen as the first recipient of the Physics Prize, while Van't Hoff and von Behring were given the Prizes for Chemistry and Medicine. In the history of science, few discoveries have put into motion an avalanche as mighty as did Röntgen's, leading from Becquerel's fundamental observation to the discovery of radium and to the birth of nuclear sciences so intimately connected with the name of Rutherford. There is no branch of science that has not benefited from the discovery of $\mathrm{X}$-rays.

The presentation of Nobel Prizes is always a great and solemn event. This year, the fiftieth anniversary of the Foundation, has been marked by even greater ceremony.

All former laureates were invited to attend; twenty-five came from abroad to join their five Swedish colleagues in celebrating this most happy event. They were headed by Max von Laue, who received the Physics Prize in 1914 for his discovery of the diffraction of X-rays by crystals, a work which immensely accelerated the rate of motion of the avalanche released by Röntgen's discovery.

In the beautifully decorated Hall of the Academy of Music, H.M. King Gustav handed over the Physics 
Prize to Powell, the Chemistry Prize to Alder and Diels, and the Prize for Physiology and Medicine to Hensch, Kendall and Reichstein.

Dr. Österling, when addressing Bertrand Russell at that occasion on behalf of the Swedish Academy of Literature, pointed out that Russell's philosophy may be said in the best sense to fulfil just those desires and intentions that Alfred Nobel had in mind when he instituted his prizes. There exist quite striking similarities between their outlooks on life. Both of them are at the same time sceptics and utopians, both take the gloomy view of the contemporary world, yet both hold fast to a belief in the possibility of achieving logical standards for human behaviour.

During the banquet in Stockholm's splendid Town Hall which followed the presentation, tribute was paid to Alfred Nobel's memory and also to the achievements of the present and former laureates. It was emphasized that the great attendance at the fiftieth anniversary ceremonies is a sign of the high esteem in which science and literature are held in Sweden, as well as an expression of deep admiration and indebtedness to those who through their brilliant achievements have enriched our minds and contributed to the welfare of human beings.

In a world torn by political disunity, the Nobel Foundation, in the spirit of its founder, has always tried to serve the cause of international understanding. Let us hope and trust that this spirit will prevail in the times to come.

G. Hevesy

\section{OBITUARIES}

\section{Prof. W. Kösters}

Prof. Wilhelm Kösters, president of the Physikalisch-Technische Anstalt at Brunswick in Western Germany, died suddenly at Münster, in Westphalia, on July 28, 1950, at the age of seventy-four. With his death the science of metrology loses one of its most energetic and experienced workers.

Wilhelm Kösters was born on April 25, 1876. He studied physics, mathematics, chemistry and mineralogy at the Universities of Münster, Greiswald and Bonn. His first appointment after graduating as Dr. phil. in 1899 was with the Kaiserliche Normaleichungskommission (Standards Committee), which later became the Reichsanstalt für Mass und Gewicht. When this establishment was amalgamated in 1917 with the Physikalisch-Technische Reichsanstalt, Kösters became director of the Department for Weights and Measures and was head of the Laboratory. Between 1899 and 1917, Kösters was scientifically active in all the Laboratories of the Committee and at an early age made valuable contributions to the methods of metrological observation and instrumentation; his contribution to the development of the larger comparator was a decisive factor in influencing subsequent measuring technique of the German length standard. In 1917 he was appointed head of the laboratory dealing with length standards.

In 1892, in Sèvres, Michelson compared the metre with the wave-length of the red cadmium line. Fabry and Perot in 1907 made a check comparison and obtained a result which was within one ten-millionth of Michelson's result. Following these measurements, the opinion prevailed in metrological circles that $a$ wave-length of a particular monochromatic light could be used instead of the international metre standard, and Kösters was a pioneer in the appli- cation of wave-length measurements for determining standard length. He saw the advantage to industry in the use of interference measuring methods, and his work resulted in 1920 in the Kösters's interference comparator built by Carl Zeiss, of Jena, and which, by its universal application, has in no mean way contributed to the fact that German industry in the field of metrology holds the position it does to-day.

In 1921 Kösters was elected a member of the Comité International des Poids et Mesures, and here he successfully advocated the use of a wave-length as a measure of standard length; at the seventh conference, held in 1927, it was decided provisionally that the metre was equivalent to $1,553,164 \cdot 13$ times the wave-length of the red line of cadmium in dry air at $15^{\circ} \mathrm{C}$., at a pressure of $760 \mathrm{~mm}$. mercury and $g=980.665 \mathrm{~cm}$. sec.-2. Kösters's definition of stan. dard gauge length was accepted internationally and, at his proposal, the yellow-green krypton line $\left(\lambda=0.5655^{\circ}\right)$ was accepted as the wave-length standard. Under Kösters's leadership this line was selected as it was found to be reproducible with the required degree of accuracy, and, indeed, at the time of his death, Kösters was still experimenting in this field using krypton-84 and -86 .

The results of Kösters's scientific work led to improvements and developments in a great number of applications : the development of standard lamps for the interference method of measuring length (1928) ; investigations on the Doppler spread of the lines of the spectrum and experiments in the cooling of lamps with solid nitrogen (1938); development of the interference double prism (1931) ; determination of the constituents of sea water by interference methods (1930); development of a comparator for the measurement of the International Ohm (1935); work on the precision measurement of the refractive index of glass plates by the interference method (1940); introduction of a standard temperature of $20^{\circ}$ C. for industrial measuring purposes, which Kösters considered specially important and which was adopted by the International Committee for Weight and Measure at Paris in 1939.

In 1948 Prof. Kösters was appointed the first president of the Physikalisch-Technische Anstalt, Brunswick (now renamed Physikalisch-Technische Bundesanstalt), which is the successor of the Physikalisch-Technische Reichsanstalt formerly situated in Berlin-Charlottenburg. He carried out the very difficult executive tasks of rehabilitating the Physikalisch-Technische Anstalt in its new surroundings at Brunswick during the critical and trying post-war period in an able manner, and his loss will be doubly felt, first, because he was an able executive, and secondly, because the load of executive duties prevented him from completing the metrological work for which he was so well known. It is characteristic of the man that he was not a writer of books; once a scientific problem on which he had been engaged extensively was resolved, his interest in that problem was finished, and perhaps through this he may be known only to the specialists, since he leaves behind remarkably little published scientific work.

E. KORNATZ

\section{Prof. W. T. Gordon}

Prof. W. T. Gordon, emeritus professor of geology in the University of London, died on December 12 at the age of sixty-six after a very short period of retirement. 